\title{
Project Selection and the Equity Objective: The Use of Social Analysis
}

\author{
JOHN WEISS*
}

\section{INTRODUCTION}

Recent developments in the methodology of social cost-benefit analysis (SCBA) have centred on the use of weights to revalue the income flows created by projects. These developments reflect the increased concern expressed by many governments in the less developed countries (LDCs) about the problems of the lowest income groups, and are an attempt to show how the objective of greater equity in income distribution can be incorporated, in addition to other more conventional objectives, in the appraisal of projects. This paper discusses the use of income weights in the light of the results of a more detailed study on SCBA in Pakistan by the author [1]. The paper is divided into three sections: the first analyses the different ways in which a weighting system can be incorporated into the appraisal of projects; the second discusses the problem of obtaining values for these weights and suggests a relatively simple approach which can be applied in Pakistan; and , finally, the third section discusses the practical significance of such procedures for decision-taking in the LDCs.

\section{INCOME WEIGHTING SYSTEM}

The SCBA shows how different government objectives can be included in the appraisal of projects. ${ }^{1} \quad$ The benefits and costs of a project are defined in terms of their contributions to the relevant set of government objectives, and will vary therefore with the objectives chosen. A distinction can be made between 'economic' analysis, where the relevant government objective is an efficient use of existing re-

*The author is a Lecturer in the Project Planning Centre at the University of Bradford, Bradford (U.K.). He is indebted to John MacArthur, David Potts and Mike Veitch for their comments on an earlier draft of this paper.

${ }^{1}$ Despite differences of terminology, presentation and emphasis, the major works on SCBA can be seen as a consistent body of literature. The presentation in this paper follows that of Squire and van der Tak [16], since the latter can be seen as a synthesis, and an extension of the earlier major publications,Little and Mirrlees [7] and the UNIDO Guidelines [9]. Henceforth, Squire and van der Tak [16] will be referred to as SVT, and Little and Mirrlees [7], as LM. 
sources, and 'social' analysis, where growth of national income and equity in its distribution are also considered [16, pp. $54-56]$. Income weights are only required for a social analysis. In appraisal at any level, all the various effects of a project must be converted into an equivalent value in terms of the numeraire or unit of account. Much of the apparent difference between works on the SCBA has been caused by the use of different numeraires. SVT follow LM in their use of income in the hands of the government, measured at world prices as numeraire. ${ }^{2}$ In theory, in a full social analysis, all private savings and consumption out of the income created by a project must be revalued in terms of the numeraire, and if equity is one of the government's objectives the weights used for this purpose will vary between different groups, depending upon their current level of income or consumption.

\section{Adjustments to Costs}

One way of conducting a social analysis is to incorporate income weights in the shadow prices given to unskilled labour and non-traded commodities. Most attention is given to unskilled labour, on the assumption that the most important income effects created by a project will be those accruing to labour moving from lower in come activities or unemployment to work on the project concerned. In an economic analysis the shadow wage $(W)$ is

$$
\mathrm{W}=\alpha \mathrm{m}
$$

where $\mathrm{m}$ is the opportunity cost of a worker, and $\alpha$ is the conversion factor (CF) required to express this opportunity cost at world prices. A CF is defined as a ratio of world to domestic prices. The CFs can be estimated for individual commodities or groups of commodities. They are required in a LM or SVT system since all items must be expressed at world prices. In a social analysis, the shadow wage becomes $\left(W^{1}\right)$;

$$
\mathrm{W}^{1}=\alpha \mathrm{m}+\beta\left(\mathrm{c}^{2}-\mathrm{c}^{1}\right)-\mathrm{d}\left(\mathrm{c}^{2}-\mathrm{c}^{1}\right)
$$

where $c^{2}$ is the new level of consumption of the worker after he has entered employment on the project,

$\mathrm{c}^{1}$ is his old level of consumption prior to obtaining employment, so that $\left(c^{2}-c^{1}\right)$ is his consumption gain,

$c^{2}$ and $c^{1}$ are measured at domestic prices and $\beta$ is the $C F$ required to express this consumption at world prices, and

$\mathrm{d}$ is the weight given to a unit of consumption at domestic prices going to the worker concerned, in relation to the numeraire. (d will vary with either the consumption or income level of the worker).

${ }^{2}$ UNIDO Guidelines [9] used private consumption at domestic prices as numeraire; this approach was followed in UNIDO studies [19] and [4]. However with this numeraire it is approach was followed in UNIDO studies [19] and [4]. Howeve
necessary to specify which private group receives the consumption.
The new shadow wage $\left(\mathrm{W}^{1}\right)$ has three elements. The opportunity cost of labour $(\alpha \mathrm{m})$ is a cost in terms of the efficiency objective since it represents a loss of income elsewhere in the economy; the extra consumption of the worker $\beta\left(c^{2}-c^{1}\right)$ is a cost in terms of growth, since it diverts resources away from saving, and, by assumption, investment. However the extra consumption of the worker is also a benefit in terms of improving income distribution, so that the value of this benefit, $d\left(c^{2}-c^{1}\right)$ is subtracted from the other items, thus lowering the shadow wage. ${ }^{3}$

Consideration of income distribution will lower $\mathrm{W}^{1}$, below what it would be if efficiency and growth were the only objective, and the poorer are the workers employed on a project the higher will be the weight $d$ and the benefit $d\left(c^{2}-c^{1}\right)$, to be subtracted from the other terms in $\mathrm{W}^{1}$ In this analysis the inclusion of the equity objective affects project selection by lowering the cost of labour, and therefore biasing the choice of projects in favour of those which employ relatively large numbers of poor workers. ${ }^{4}$

In the case of non-traded commodities used as inputs by a project, their shadow price in an economic analysis will normally be determined by the resources used in their production valued at world prices, or equivalent world prices. For nontraded commodity $\mathrm{x}$ the shadow price can be defined as:

$$
P_{x}=\sum_{i} a_{i} P_{i}+\sum_{j} a_{j} P_{j}+a_{\ell} W+K \cdot r \quad \ldots
$$

where $\sum_{\mathrm{i}}$ are the traded inputs (i) used in the production of non-traded goods $\mathrm{x}$,

$a_{i}$ is the number of units of $i$ per unit of $x$,

$\mathrm{p}_{\mathrm{i}}$ is the world price (c.i.f. or f.o.b.) for traded good $\mathrm{i}$,

$\sum_{j}$ are the non-traded inputs $(j)$ used in the production of $x$,

$a_{j}$ is the number units of $j$ per unit of $x$,

$p_{j}$ is the shadow price of $\mathbf{j}$ (calculated for $\mathbf{j}$ in the same way as for $\mathbf{x}$ ),

$\mathrm{a}_{\ell}$ is the number of workers required per unit of $\mathrm{x}$,

$\mathrm{W}$ is the shadow wage [ calculated as in equation (1) ],

$\mathrm{K}$ is the value of capital stock at world prices required per unit of $\mathrm{x}$, and

$r$ is the percentage opportunity cost rate of return on capital.

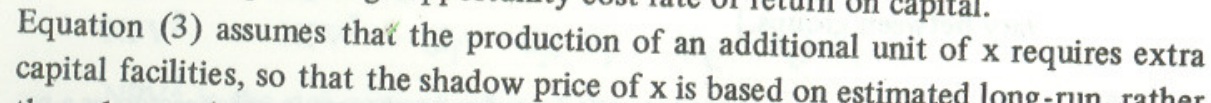
than than short-run marginal costs. Capital costs are shown separately from the input
items $i$ and $j$.

only consumption weights are required in going to unskilled labour is assumed to be consumed, $\mathrm{cal}$ in principle although normally it is taken analysis. The treatment of skilled labour is identiers are raised by a project different assumptions that $\mathrm{c}^{2}=\mathrm{c}^{1}$. Where the incomes of skilled work4SVT [16, pp. 78-87] give another definition of the shadow wage which includes the
cost of foregone leisure. 
In a social analysis the shadow price of non-traded goods must include an allowance for the income changes created as a result of the increased production of these commodities. These income changes can take various forms. Workers employed as a result of the extra production of a non-traded good will find their income increased if they move from lower income activities; owners of capital may find that they earn a higher rate of profit in the production of the non-traded good than they could in other sectors; consumers may also be affected if extra production of the non-traded good leads to price changes in other sectors $;^{5}$ the government may also gain extra tax revenue paid by producers or consumers. In principle all these income changes should be revalued by the weights for private savings and consumption relevant for the groups concerned.

One simplifying assumption which can be adopted is that private savings is equal in value to government income. ${ }^{6}$ If this is so additional costs or benefits, as a result of income changes created by the production of a non-traded good, can arise only through changes in private consumption. This assumption is used in this paper, so that attention can be concentrated on consumption weights. Adopting this assumption, in a social analysis, the new shadow price of $x,\left(p_{X}^{I}\right)$ will be

$$
P_{x}^{I}=\sum_{i} a_{i} P_{i}+\sum_{j} a_{j} P_{j}^{I}+a_{\ell} W^{I}+K \cdot r^{I}+\sum_{3}\left(\beta_{3}-d_{3}\right) C_{3} \ldots
$$

where $P_{j}^{I}$ is the shadow price of $j$ in a social analysis,

$\mathrm{W}^{\mathrm{I}}$ is the new shadow wage [calculated from equation (2)],

$\mathrm{r}^{\mathrm{I}}$ is the opportunity cost of capital in a social analysis, ${ }^{7}$

$\Sigma$ are the private groups, excluding labour, whose income is affected by production of $\mathrm{x}$,

$\mathrm{C}_{3}$ is the value at domestic prices of the extra consumption of each group,

$\beta_{3}$ is the CF required to express the cost of this extra consumption at world prices, and

$d_{3}$ is the weight which expresses the value of a unit of consumption at domestic prices in units of the numeraire. [As in equation (2), $d$ will vary between groups.]

${ }^{5}$ Mirrlees [10] stresses the potential significance of price changes in other sectors as a result of extra production of a non-traded good.

${ }^{6}$ See $[16$, p. 116]. Both $[7]$ and [16] discuss ways of giving private savings a weight of $\gtrless 1.0$; see $[7$, pp. 192-204] and [16, pp. 71-72]. There are considerable practical problems in estimating weights for savings.

${ }^{7}$ In principle, the opportunity cost of capital will differ between an economic and a social analysis, since benefits and costs are defined differently; see [16, pp. 75-76].
In equation (4) whether the extra consumption generated by a project will lower or raise the shadow price of $\mathrm{x}$ in relation to its value in an economic analysis will depend upon the value of extra consumption in relation to the numeraire. If the benefit of extra aggregate consumption exceeds its costs $\Sigma_{3}\left(d_{3}>\beta_{3}\right)$, it will be subtracted from the other items in equation (4), whilst if the cost exceeds the benefit $\Sigma\left(\beta_{3}>d_{3}\right)$ the income changes created by the production of $x$ will have a negative social value and will raise the shadow price of $\mathrm{x}$. Consumption gains for workers employed in the production of $\mathrm{x}$ do not need to be considered separately since thev will have been revalued already in the shadow wage, $\mathrm{w}^{1}$.

Poor groups will have a relatively high value of $d$, so that their extra consumption should produce a benefit to be deducted from the cost items in the shadow price of $\mathrm{x}$. In this way the use of adjusted shadow prices for non-traded goods is intended to have the effect of lowering the shadow price of goods, whose additional production leads to income and consumption gains for poor groups. As in the treatment of labour this is a way of biasing the selection of projects in a particular direction; in this case in favour of those which use such non-traded goods. ${ }^{8}$

\section{Adjustments to Benefits}

An alternative procedure for applying social analysis is to revalue the benefit rather than the cost stream of a project. Instead of adjusting individual shadow prices to take account of income effects, the income changes for all groups affected by a project must be identified and adjusted by the relevant weights. ${ }^{9}$ An ecanomic analysis at shadow prices equal to the opportunity costs of commodities and factors, will give the net contribution of a project to national income. All income gains or losses in the economy attributable to the project must be allocated between different groups, and the extra savings and consumption of each group estimated and revalued in terms of the numeraire. The approach can be illustrated algebraically with a simple example.

$$
\begin{array}{ll}
\mathrm{NPV}^{2} & =\mathrm{Y}_{\mathrm{g}}+\mathrm{Y}_{\mathrm{f}}+\mathrm{Y}_{\ell} \quad \ldots \\
\mathrm{Y}_{\mathrm{f}} & =\mathrm{C}_{\mathrm{f}}+\mathrm{S}_{\mathrm{f}} \\
\mathrm{Y}_{\ell} & =\mathrm{C}_{\ell}+\mathrm{S}_{\ell} \\
\mathrm{NPV}^{3} & =\mathrm{NPV}^{2}-\left(\beta_{\mathrm{f}}-\mathrm{d}_{\mathrm{f}}\right) \mathrm{C}_{\mathrm{f}}-\left(\beta_{\ell}-\mathrm{d}_{\ell}\right) \mathrm{C}_{\ell} \ldots .
\end{array}
$$

$\mathrm{NPV}^{2}$ is the net present value of the project in an economic analysis. It is assumed that only three groups are affected by the project, the government, farmers and labour. The income changes of these groups are $\mathrm{Y}_{\mathrm{g}}, \mathrm{Y}_{\mathrm{f}}$, and $\mathrm{Y}_{\ell}$, respectively. These changes can be positive or negative. The income changes for the private

${ }^{8}$ In the SVT and LM system non-traded outputs of a project will be valued at consumer willingness to pay; after being converted from domestic into world prices, in principle, this measure could also be adjusted to allow for different income levels of consumers.

${ }^{9}$ This approach was used in [9] and has been adopted by [3] and [4]. 
groups, farmers and labour can be divided between savings and consumption, using estimates of marginal savings propensities. $\quad \mathrm{C}_{\mathrm{f}}$ and $\mathrm{C}_{\ell}$ are the extra consumption, and $S_{f}$ and $S_{\ell}$ are the extra savings for farmers and labour. The net present value of the social analysis, $\mathrm{NPV}^{3}$, is derived from $\mathrm{NPV}^{2}$ by adding the adjustments made to the income flows created by the project. Government income, $\mathrm{Y}_{\mathrm{g}}$, is not adjusted since it is the numeraire, nor are private savings, as they are assumed to be equal in value to government income. Only changes in private consumption can create additional benefits or costs depending upon whether the costs of extra consumption, determined by the conversion factors $\left(\beta_{\mathrm{f}}\right.$ and $\left.\beta_{\ell}\right)$ exceed the benefits, determined by the consumption weights $\left(\mathrm{d}_{\mathrm{f}}\right.$ and $\left.\mathrm{d}_{\ell}\right)$. In this approach labour and non-traded goods will be valued at the shadow prices of an economic analysis $\mathrm{W}$, and $\mathrm{P}_{\mathrm{X}}$, and not at shadow prices adjusted for income changes, $\mathrm{W}^{\mathrm{I}}$ and $\mathrm{P}_{\mathrm{X}}^{\mathrm{I}}$.

Experience in applying this approach in Pakistan [19] suggests a number of points.

(i) It may be useful to define the NPV of an economic analysis as

$$
\mathrm{NPV}^{2}=\mathrm{NPV}^{1}+\triangle \mathrm{NPV} \cdots
$$

where $\mathrm{NPV}^{1}$ is the NPV at domestic market prices. Equation (7) states that $\mathrm{NPV}^{2}$ is the net present value at market prices plus the difference between the net present value at shadow and at market prices $(\triangle \mathrm{NPV})$. One can identify two separate types of income effect created by a project; one due to the market prices paid for inputs and outputs, and the other due to the difference between shadow and market prices. For example the cost to a project of employing a worker is the market wage; however the gain to the worker is often taken to be difference between the market and the shadow wage. Distinguishing between these two causes of income flow may help in distributing the gains and losses from a project between different groups.

(ii) It may not be possible to allocate precisely all $\mathrm{NPV}^{2}$ to different groups, so that the residual income changes have to be allocated to a particular group. If the project concerned is in the public sector, it is convenient if the government is the group used for this purpose. 10

(iii) For many industrial projects the main income changes for private sector groups are likely to be the result of the direct employment of labour on a project, or the additional production of non-traded goods.

It is clear that if the same assumptions are adopted both procedures for social analysis will give the same results. The procedure of adjusting income flows rather than individual shadow prices has a number of practical advantages, however. It allows a clearer presentation of the estimated income effects of a project. Decisiontakers can see readily the estimated extent to which low or high income groups are affected. Furthermore since income changes created by a project are rarely known

${ }^{10}$ However this approach cannot be used indiscriminately for all types of income changes. It would not be legitimate to allocate to the government income gains to private consumers, simply because the particular income levels of the consumers could not be identified. precisely, it is important to have data presented in a form that allows sensitivity analysis to be applied easily. It may be useful to test the sensitivity of an appraisal to both the assumed income and consumption changes, and the weights given to these. Allowing for income changes through adjusted shadow prices does not preclude the use of sensitivity analysis, but it makes its application more complicated.

A third alternative for incorporating distributional considerations in project appraisal is to adjust for the production as opposed to the income effects of projects. Basic goods or services consumed by the poor can be treated as 'merit wants' and given an extra value above their opportunity cost shadow prices. ${ }^{11}$ The problem with this approach is that there is still no satisfactory means of identifying the premium to be given to such goods or services, and for this reason it will not be discussed further here.

\section{THE DERIVATION OF CONSUMPTION WEIGHTS}

LM obtain consumption weights by assuming first that there is certain level of annual per capita consumption, termed the base level of consumption, at which the government is indifferent between income consumed by people at the base level and the same income going to the government itself. Secondly they assume that the government's valuation of additional units of consumption falls at a constant percentage rate for a given percentage rise in the level of consumption of the recipient. In technical terms, the latter assumption implies a government utility function with respect to increases ir consumption, of constant negative elasticity. The formula for consumption weights is ${ }^{12}$

$$
\mathrm{d}_{\mathrm{i}}=\frac{(\mathrm{b})^{\mathrm{n}}}{\mathrm{c}_{\mathrm{i}}} \ldots
$$

where $d_{i}$ is the consumption weight of group $i$,

$\mathrm{b}$ is the base level of consumption,

$c_{i}$ is the average level of consumption for group $i$, and

$\mathrm{n}$ is the assumed elasticity of the government utility function for consumption.

Groups on the base level have a weight of 1.0 , since their consumption is equal in value to the numeraire, whilst those above the base level have a weight of $<1.0$, and those below it a weight $>1.0$.

Average consumption levels of different groups can, in principle, be calculated from observable data, so that the weights, $d_{i}$, will be determined by the choice of values for $\mathrm{b}$ and $\mathrm{n}$. It is acknowledged that $\mathrm{n}$ is a subjective parameter which reflects the degree of government commitment to redistribute income. The higher the value

${ }^{11}$ This possibility is discussed in Veitch [18].

${ }^{12}$ See [7, pp. $\left.234-242\right]$. An alternative formula will be required if one is considering large, non-marginal changes in consumption; see [16, p. 65] 
of $\mathrm{n}$ the higher will be the weight given to the poorest groups, and the lower the weight given to the richest. A 'reasonable' range of values for $\mathrm{n}$ is taken to be 0.5 to $2.0\left[16\right.$, p. 103].$^{13}$ A major obstacle to applying the LM approach is in identifying the value of $b$. It is suggested that it can be inferred from existing government policies on taxes and subsidies, and that it will lie between the income level at which income tax payments commence, where the government takes money from individuals, and the level at which individuals receive money from the government in the form of welfare subsidies. However in many LDCs such an income range cannot be defined clearly. In Pakistan in 1977 income tax payments commenced at the level of Rs. 12,000 per year, substantially above the average income level, whilst the main form of subsidies, purchases of wheat and sugar at controlled prices from ration shops, were available to all irrespective of income level. A relatively narrow range of income within which the base level might lie could not be identified for Pakistan in [19].

SVT do not derive consumption weights in the same way as LM. Instead of identifying a base level of consumption, they relate private consumption to government income in two stages. First the value of a unit of the numeraire is calculated in terms of units of consumption at domestic prices going to an individual with the national average level of consumption per capita. Secondly they use the same government utility function as LM, but compare the consumption of a particular group with the national average rather than an estimated base level.

The value of a unit of consumption at domestic prices going to group $\mathrm{i}$, in relation to the numeraire, is given by $d_{i} / v$, where $d_{i}$ is the value of a unit of consumption going to group $\mathrm{i}$ in relation to a unit going to the average consumer, and $\mathrm{v}$ is the value of a unit of the numeraire in terms of units of consumption at domestic prices going to average consumers.

The weight $d_{i}$ is determined by the relationship

$$
\mathrm{d}_{\mathrm{i}}=\frac{(\overline{\mathrm{c}})^{\mathrm{n}}}{\mathrm{c}_{\mathrm{i}}} \ldots
$$

where $\bar{c}$, the national average level of consumption, has replaced $b$, as the point of comparison with $\mathrm{c}_{\mathrm{i}}$.

The substitution of $\bar{c}$ for $b$ avoids the need to infer a base level of consumption from government policies. However problems in estimating $b$ are replaced by problems in estimating the value of government income in relation to private consumption, $v$. SVT suggest that $\mathrm{v}$ can be calculated from a formula which relates the value of a unit of investment to the present value of the stream of consumption generated by the investment. This approach assumes that either all government income is invested or that, at the margin, the government allocates its resources optimally, so

${ }^{13} \mathrm{~A}$ government interested in income redistribution will have an implicit valuation of $\mathrm{n}>0$. It is argued that values of $\mathrm{n}=2.0$ will give unrealistically high and low weights for very poor and very rich groups. that all government expenditure, wheter investment or current expenditure, is of equal value. A number of different formulae are given for $\mathrm{v}$, but the main one is that for the shadow price of investment in the UNIDO Guidelines. ${ }^{14}$

$$
v=\frac{q-s q}{i-s q} / \beta \quad \ldots
$$

where $\mathrm{q}$ is the marginal product of capital in the public sector, at world prices,

$\mathrm{s}$ is the marginal propensity to reinvest in the public sector,

$\mathrm{i}$ is the rate at which the government discounts future consumption, and

$\beta$ is the conversion factor which translates consumption expenditure at domestic prices into world prices.

The value of investment (and by assumption government income) is determined by the annual returns on investment $(q)$, the proportions of these which are saved (s), and consumed (1-s), and the extent to which the government places a lower value on consumption in the future (i). The expression

$$
\frac{q-s q}{i-s q}
$$

gives the present value of the stream of units of consumption generated by a unit of investment. However this consumption is measured at world prices, because (q) the annual surplus of a project is at world prices. Since what is required is a comparison between the value of a unit of government income at world prices and units of private consumption at domestic prices, the stream of consumption generated by a unit of investment must be converted into domestic prices by dividing by $\beta$.

Equation (10) is based on the simplifying assumptions,

(i) that the value of all parameters in the formula (q, s, i) remain constant; and

(ii) that all the consumption generated by an additional unit of investment accrues to those with a level of consumption equal to the national average.

Despite these simplifications there are major problems in practice in estimating v. In principle $\mathrm{q}$ and $\mathrm{s}$ can be calculated from observable data. $\mathrm{q}$ will be the internal rate of return calculated at world prices on the marginal public project; rough estimates of $\mathrm{q}$ can be obtained from industrial census data or from examinations of past project appraisals. Estimates of the future savings propensity, $\mathrm{s}$, can be taken from targets in national plans, possibly adjusted downwards if these are judged to be unrealistically high. A conversion factor for consumption $\beta$, will be required in calculating other shadow prices. Despite difficulties in estimating $\mathrm{q}, \mathrm{s}$ and $\beta$, accurately, the major conceptual problem arises in the treatment of $i$, the government's discount rate for consumption. $i$ is a subjective parameter which expresses the government's valuation of consumption at different points of time. However

\footnotetext{
${ }^{14}$ See $[16$, pp. 104-106]. A more detailed discussion is given in $[9$, pp. 173-200]
} 
no government expresses its objectives in terms of a particular consumption discount rate. A formula given for $\mathrm{i}$ is ${ }^{15}$

$$
\mathrm{i}=\mathrm{ng}+\mathrm{p} \quad \ldots
$$

where $\mathrm{n}$ is the elasticity of the government's utility function for consumption [as in equations (8) and (9)],

$\mathrm{g}$ is the annual rate of growth of per capita consumption, and

$\mathrm{p}$ is the government discount rate for pure time preference.

The logic of this formula is that the rate at which a government discounts future consumption will depend upon firstly the extent to which average levels of consumption are growing over time $(\mathrm{g})$; secondly the rate at which the government's valuation of extra consumption falls as the consumers who receive it get better off, (n); and thirdly the extent to which the government feels that future consumption is less valuable simply because it occurs in the future rather than the present (p). A value of $\mathrm{g}$ can be obtained from plan projections or from extrapolations of past trends, and a value of $\mathrm{n}$ will be required in order to derive a set of consumption weights from equations (8) and (9). The problem with the formula for $i$ is that $p$, the government rate of pure time preference, is also a subjective parameter, and there is little evidence on its likely numerical value.

Since governments do not specify their objectives in terms of particular rates of discount for future consumption, and the formula for $\mathrm{i}$ contains an unknown parameter, the value of $\mathrm{i}$ is highly uncertain. ${ }^{16}$ Using equation (10) it is possible to narrow the range of values for $i$; i must be greater than sq, and less than $q$. The lower value is given by the fact that if $\mathrm{i}<\mathrm{sq}$, the extra consumption created by a unit of investment will grow at a faster compound rate than the discount rate used to express it at a present value; in these circumstances $\mathrm{v}$ will tend to infinity. At the upper limit, if $\mathrm{i}=\mathrm{q}, \mathrm{v}$ will equal 1.0, so that a unit of investment (and government income) will be worth the same as a unit of consumption going to the average consumer. This contradicts the assumption of a savings constraint on growth normally adopted in SCBA. However the possible range of values for $\mathrm{i}$ can be relatively wide.

The problem of estimating $\mathrm{v}$ can be illustrated for Pakistan. Alternative values of $q$ of 10 percent and 12 percent are used. These are rough estimates of the returns to marginal public sector projects. ${ }^{17}$ The values taken for $s$ are 23 percent and 15 percent. A marginal savings propensity of 23 percent is the target

${ }_{16}^{15}$ See $[16$, pp. $139-140]$.

${ }^{16}$ The procedure for identifying i suggested in [9] is to infer a value from an examination of past government decisions on projects. This is very difficult in practice and implies an unreal${ }_{17}$ These values were istic
ingined

Government of Pakistan. They should not be interpreted the staff of the Planning Commission, ty cost of capital in Pakistan. They should not be interpreted as precise estimates of the opportunity cost of capital in Pakistan. For a detailed explanation of their derivation, see [19]. for the whole economy in the Fifth Plan, whilst one of 15 percent represents a rate closer to levels achieved in the past $[12, \mathrm{p} .8]$. The conversion factor for consumption is approximated by an average conversion factor for all traded goods used in Pakistan. This was calculated to be 0.85 in 1976-1977, using the formula for the Standard Conversion Factor given by $[16$, p. 95$] .^{18}$

Khan [5] estimated i to be 4 percent for Pakistan. His approach ignored pure time preference by assuming that $\mathrm{i}=\mathrm{ng}$; $\mathrm{n}$ was taken to be close to 1.0 , and the annual rate of growth of consumption per capita from 1959-1960 to 1969-1970, of 3.7 percent, was extrapolated into the future, as a value for $\mathrm{g}$. This rate of growth is relatively high since the real rate of growth of consumption per capita over the period 1971-1972 to $1975-1976$ was around 2 percent per year. ${ }^{19}$ Furthermore the approach is only partial since it ignores $p$, the elemient of pure time preference, in the consumption discount rate.

Here in calculating $v$ for Pakistan, $\mathrm{i}$ is treated as an unknown, and three alternative values of 3 percent, 5 percent and 7.5 percent are used to test the sensitivity of $v$ to different values of $i^{20} \quad$ These values are within the range specified by the constraint that $\mathrm{i}>\mathrm{sq}$, and $\mathrm{i}<\mathrm{q}$. The results of the calculations for $\mathrm{v}$ are given in Table 1 .

Table 1

Alternative Values for Government Income in Relation to Average Consumption (v)

Conversion Factor Translating Consumption Expenditure at Domestic Prices into World Prices $(\beta)=0.85$

Discount

Rate for

Future

Consumption

\begin{tabular}{cc}
\hline Marginal Propensity to Reinvest in Public Sector (s) \\
\hline$s=15 \%$ & $s=23 \%$ \\
\hline
\end{tabular}

\begin{tabular}{ccccc} 
& $\begin{array}{c}\text { Marginal Product of } \\
\text { Capital in the Public } \\
\text { Sector at World } \\
\text { Prices (q) }\end{array}$ & $\begin{array}{c}\text { Marginal Product of } \\
\text { Capital in the Public } \\
\text { Sector at World } \\
\text { Prices (q) }\end{array}$ \\
\cline { 2 - 5 } & $\mathrm{q}=1.0 \%$ & $\mathrm{q}=12 \%$ & $\mathrm{q}=10 \%$ & $\mathrm{q}=12 \%$ \\
\hline $\mathrm{i}=3 \%$ & 6.7 & 10.0 & 12.9 & 45.3 \\
$\mathrm{i}=5 \%$ & 2.8 & 3.8 & 3.3 & 4.8 \\
$\mathrm{i}=7.5 \%$ & 1.6 & 2.1 & 1.8 & 2.2 \\
\hline
\end{tabular}

${ }^{18}$ The Standard Conversion Factor is the inverse of the Shadow Exchange Rate; see [19] for details of the calculations.

${ }^{19}$ See [19] for details of the calculations.

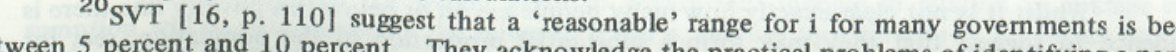
tween 5 percent and 10 percent. They acknowledge the practical problems of identifying a par-
ticular value. 
The value of $v$ is highly sensitive to the choice of $i$, and when $i$ is only slightly greater than sq, v becomes very high. Using equation (10) and the values of the parameters given in Table 1, one unit of government income can be worth as much as 45.3 units of consumption going to average consumers or as little as 1.6 units. This is much too wide a range of possible values for practical analysis. For this reason one can question the usefulness of the SVT approach to consumption weights, as it involves the highly uncertain parameter $\mathrm{v}$.

A simple alternative is to redefine the concept of a base level of consumption as a minimum subsistence level of per capita consumption. Use of this approach means that $b$ becomes a poverty line rather than a consumption level inferred from an examination of government policies. Consumption weights will be determined by the average consumption level of a particular group in relation to the minimum subsistence level, and the value assumed for $\mathrm{n}$, the elasticity parameter used to reflect the government's commitment to equity. Those on the poverty line will have a weight of 1.0 , whilst those above it will have a weight $<1.0$, and those below it a weight $>1.0$. Weiss [19] adopted this approach to obtain a series of consumption weights for Pakistan. The poverty line level of per capita consumption was taken to be Rs. 1080 at 1977 prices. $^{21}$ This was based on the estimated minimum subsistence income level of Rs. 400 per month at 1976 prices, for a family of 5, given in the first version of the Fifth Plan [11, p. 15].22 This figure was escalated to 1977 prices by the increase in the wholesale price index between January 1976 and July 1977 to give Rs. 450 per month for a farnily of five, or Rs. 1080 per annum per capita. ${ }^{23}$

To obtain values for the consumption weights for different groups from equation (8), it is necessary to assume a value for $n$. There is no satisfactory way of estimating $\mathrm{n}$; all that is possible is to decide whether weights derived from particular values of $\mathrm{n}$ reflect adequately government objectives on equity. Table 2 shows the consumption weights for groups in Pakistan, differentiated by their average per capita consumption at 1977 prices, using values of $\mathrm{n}$ of $0.5,1.0$, and 1.5, and $\mathrm{b}=$ Rs. 1080 per year. In practice in deriving consumption weights it seems more important to choose a single value of $n$, explain its implications to decision-takers and use it consistently in appraisals, rather than debate whether $\mathrm{n}$ should be 0.5 , 1.0 or 1.5 . If sensitivity analysis using different values of $n$ is carried out, there is the danger that decisions on different projects will be taken on the basis of different values of $n$. In [19], a single value of $n=1.0$ was used on the grounds that it gives an intuitively understandable set of weights; $n=1.0$ implies that the weight placed by the government on an additional Rupee of consumption falls in direct pro-

${ }^{21}$ All values in the study were at 1977 prices.

22This income level is referred to as one required to sustain "life without privation".

23 Whilst it is not clear exactly how many people are on or below this poverty line there is evidence to suggest that they may form a substantial proportion of the population; see, for example, Alauddin [1]
Table 2

Consumption Weights for Different Groups $\left(\mathrm{d}_{\mathrm{i}}\right)$ where $d_{i}=\left(\frac{b}{c_{i}}\right)^{n}$

\begin{tabular}{|c|c|c|c|c|}
\hline \multirow{2}{*}{$\begin{array}{l}\text { Average } \\
\text { Consumption } \\
\text { level of } \\
\text { group }\end{array}$} & \multirow[t]{2}{*}{$\begin{array}{c}\text { Base Level } \\
\text { of } \\
\text { Income }\end{array}$} & \multicolumn{3}{|c|}{$\begin{array}{l}\text { Consumption Weight }\left(\mathrm{d}_{\mathrm{i}}\right) \text { when } \\
\text { Value of } \mathrm{n}=\end{array}$} \\
\hline & & 0.5 & 1.0 & 1.5 \\
\hline (Rs./Year) & (Rs./Year) & & & \\
\hline $\mathrm{c}_{\mathrm{i}}$ & b & $\mathrm{d}_{\mathrm{i}}$ & $\mathrm{d}_{\mathrm{i}}$ & $\mathrm{d}_{\mathrm{i}}$ \\
\hline 600 & 1080 & 1.34 & 1.80 & 2.40 \\
\hline 800 & 1080 & 1.16 & 1.35 & 1.57 \\
\hline 1080 & 1080 & 1.00 & 1.00 & 1.00 \\
\hline 1200 & 1080 & 0.95 & 0.90 & 0.85 \\
\hline 1600 & 1080 & 0.82 & 0.67 & 0.55 \\
\hline 2000 & 1080 & 0.73 & 0.54 & 0.40 \\
\hline 4000 & 1080 & 0.52 & 0.27 & 0.14 \\
\hline 8000 & 1080 & 0.37 & 0.13 & 0.05 \\
\hline
\end{tabular}

portion with the rise in the consumption level of the recipient. In other words a Rupee received by someone in a group with an average consumption of Rs. 600 will be worth twice as much as a Rupee received by someone in a group with an average consumption level of Rs. 1200.

This approach to consumption weights utilizes a more practicable concept of the base level of consumption than does LM, and avoids the use of the highly uncertain parameter $\mathrm{v}$. It derives consumption weights from judgements on $\mathrm{b}$, the base level of consumption, and $n$, the elasticity parameter of the government's utility function. ${ }^{24}$ The approach is relatively simple to apply in practice although if it is adopted, the realism of the chosen values for $\mathrm{b}$ and $\mathrm{n}$ must be discussed.

\section{SIGNIFICANCE OF SOCIAL ANALYSIS}

The first two sections have shown how equity objectives can be incorporated into the appraisal of projects and discussed ways of obtaining consumption weights. They have not gone outside the technical framework of SCBA and questioned the significance of such procedures. It is clear from equation (6) that the use of a consumption weighting system will only have a major effect on the NPV and internal rate of return of projects which generate substantial income and consumption chang-

${ }^{24}$ In this approach the weight given to government income in relation to average consumption will be determined by the values of $\mathrm{b}$ and $\mathrm{n}$, and not by estimates of the future productivity of public sector investment, as in the formula for v. [Equation (10)]. 
es for private sector groups. Such projects are likely to have some or all of the following characteristics:

(i) the employment of large numbers of unskilled workers who would otherwise be employed in low income activities or openly unemployed.

(ii) the use of large amounts of non-traded inputs whose production is expanded to meet the requirements of the project.

(iii) the production of non-traded goods which increase the income of their.users either through price changes or the extra production which they generate.

Projects with these characteristics are found most commoniy in the agricultural, agro-industrial and some infrastructure sectors. Industrial projects in general have a relatively weak effect in terms of income distribution since they tend to employ relatively few unskilled workers, use a high proportion of traded to non-traded inputs, and produce traded goods as outputs. Much of the income effects of public sector industrial projects will be felt by the government, rather than private groups.

To apply a consumption weighting system it is necessary to have not only a consistent set of weights, but also reasonably accurate estimates of the income and consumption changes created by a project. ${ }^{25}$ This may be relatively straightforward for the workers employed directly on a project, but is likely to be considerably more complicated in the case of the income effects resulting from the use or production of non-traded goods. A number of examples may illustrate the point. A new sugar mill project may stimulate additional production of sugarcane. Estimating the extra income received by faimers as a result of this expansion in sugarcane cultivation will involve not only estimates of the revenues and costs from sugarcane cultivation itself, but also estimates of the net income from other crops foregone as a result of the shift to sugarcane. ${ }^{26} \quad$ An irrigation project may raise farm incomes through the extra production made possible by the supply of irrigation water. In both cases it will be necessary to estimate not only the total extra income, but also its distribution between farms. A road project may reduce transport costs for road haulage companies and thus lead to a recuction in freight charges, which is passed on to consumers in lower prices for final goods. Estimating which consumers gain as a result of these price reductions can be very difficult. Finally some of the major income effects of industrial projects are likely to be through their use of workers in their construction phase, and in the distribution of their finished output. Estimation of these effects requires data on the labour component of construction and distribution costs. In cases such as these social analysis will require detailed information on the cost structure of non-traded sectors, such as Construction, Power, Irrigation, Road and Rail Transport, and Distribution, and detailed farm budget data on both traded and non-traded crops. Such data can come from surveys of particular sectors and

${ }^{25} \mathrm{MacArthur}[8]$ illustrates some of the complexities involved in estimating the income effects of a land settlement scheme.

${ }^{26}$ These problems are examined in Weiss [19] and Potts [14]. crops, and from a relatively detailed input-output table. However in many LDCs the basic data requirements for a social analysis are lacking. In Pakistan, for example, detailed information on the main non-traded sectors are not available, and the most recent input-output table dates from 1962-1963. ${ }^{27}$

It is possible to question the extent to which even economic analysis is likely to be applied to new public sector projects. SCBA in the context of LDCs was developed chiefly to appraise 'directly productive' projects in the industrial and agricultural sectors. ${ }^{28}$ In the case of projects which produce traded goods, it is relatively simple to use world market prices to value output. Projects which produce nonly simple to use worle since it is necessary to value their production in terms of its effect on domestic users or consumers. Estimation of production and Power projects, for example, can be difficult, benefits in Transport, Irrigation and Power projects, for example, can be difficult, even before considerations of income distribution are introduced. ${ }^{29}$ Therefore even if a comprehensive set of national shadow prices are estimated for a particular country it is unlikely that all new public sector projects could be appraised by even an economic analysis. Given the additional data requirements of social analysis it appears unrealistic to suggest that for many LDCs more than a minority of public sector projects could be appraised in this way. Where social analyses can be applied they will probably have the effect of shifting some investment expenditure from the industrial sector to agriculture and, possibly, to some infrastructure activities. However, one can question the quantitative impact this is likely to have on the problems of poverty and inequitable income distribution.

The conventional justification for the use of social as opposed to economic analysis, is that in their policy statements governments often lay considerable stress on the equity objective, but that they are constrained by various political pressures from taking direct measures to redistribute income. It is argued that it is more difficult to shift the distribution of existing assets than to direct the creation of new assets in favour of the poor. Project selection is, therefore, seen as an important complement to more direct measures, such as fiscal policy or land reform, for which the government's freedom of action is limited..$^{30}$

It is clear that in some circumstances the use of a consumption weighting system can have a progressive effect in terms of the distribution of income. However this fact should not divert attention from the need to implement other measures. Project selection is very much a 'second-best' policy instrument for coping with the problems of poverty and inequality. The living standards of poor groups in most LDCs can be raised most rapidly by policies to change land ownership rights and

${ }^{27}$ Weiss [19] describes the data available, and an attempt to revise the input-output table to $1969-1970$.

${ }^{28}$ The original work by Little and Mirrlees [6] was titled "A Manual of Industrial Project Analysis". Many of the ideas underlying SCBA were generated by studies of industrialization in LDCs.

${ }^{29}$ Anand [2] and Porter and Walsh [13] illustrate economic analyses of road and water projects, respectively.

example, see Ray and van der Tak [15]. 
tenant-owner relations, and to ensure the provision of basic consumer goods, at prices that the poor can afford. In the foreseeable future in most LDCs, detailed SCBA techniques will be applied to only a minority of new investment expenditures, and only some of these investments will be of the type to which social analysis can be applied. The reality of many LDCs is that the balance of class forces prevents effective redistribution in favour of the poor. ${ }^{31}$ Redistribution via arithmetic, in the form of social analysis, may appear a painless alternative to the conflict associated with radical reforms or the organizational problems of rationing or subsidy schemes. The important point is that the useful, although subsidiary, role of social analysis should not divert attention away from the need to overcome the constraints on more effective policy measures.

\section{REFERENCES}

1. Alauddin, Talat. "Mass Poverty in Pakistan - A Further Study." Pakistan Development Review. Vol. XIV, No.4. Winter 1975.

2. Anand, Sudhir. Appraisal of a Highway Project in Malaysia: Use of the LittleMirrlees Procedures. Washington: World Bank. July 1975. (World Bank Staff Working Paper No. 213).

3. Great Britain. Ministry of Overseas Development. A Guide to the Economic Appraisal of Projects in Developing Countries. London: Her Majesty's Stationery Office. 1977.

4. Hansen, John R. Guide to Practical Project Appraisal. New York: UNIDO. 1978.

5. Khan, S. R. "An Estimate of the Shadow Wage Rate in Pakistan." Pakistan Development Review. Vol. XIII, No.4. Winter 1974.

6. Little, Ian M. D. and James A. Mirrlees. Manual of Industrial Project Analysis in Developing Countries. Vol. II. Paris: OECD. 1968.

7. Little, Ian M. D. and James A. Mirrlees. Project Appraisal and Planning for Developing Countries. London: Heinemann Educational Books. 1974.

8. MacArthur, J. D. “Appraising the Distributional Aspects of Rural Development Projects: A Kenya Case Study." World Development. Vol. 6, No. 2. February 1978.

9. Marglin, S., A. K. Sen and P. Dasgupta. Guidelines for Project Evaluation. New York: UNIDO. 1972.

10. Mirrlees, James A. "Social Benefit-Cost Analysis and the Distribution of Income." World Development. Vol. 6, No. 2. February 1978.

11. Pakistan. Planning Commission. Draft Fifth Five Year Plan, 1976-1981. (First Version). Vol. I. Islamabad. 1976.

${ }^{31}$ Stewart [17] argues that if project appraisal were to become an effective means of redistributing income, the same class forces which operate to block other policy measures, are likely to constrain the use of social analysis.
12. Pakistan. Planning Commission. Fifth Five Year Plan (1978-1983). Islamabad. June 1978.

13. Porter, R. and M. Walsh. "Cost Effectiveness Analysis in Practice: A CaseStudy of Domestic Water Supplies in an African Country." World Development. Vol. 6, No. 2. February 1968.

14. Potts, D. "The Supply of Sugarcane and the Estimation of its Shadow Price: A Case-Study from Pakistan.” Islamabad: Project Planning Centre. November 1978. (Mimeographed).

15. Ray, Anandarup and Herman G. van der Tak. "A New Approach to the Economic Analysis of Projects.” Finance and Development. March 1979.

16. Squire, Lyn and Herman G. van der Tak. Economic Analysis of Projects. Baltimore, Maryland (USA) and London: The Johns Hopkins University Press. 1975. (A World Bank Research Publication)

17. Stewart, Frances. "A Note on Social Cost-Benefit Analysis and Class Conflict in LDCs." World Development. Vol. 3, No. 1. January 1975.

18. Veitch, Mike. "Cost-Benefit Analysis and Basic Needs." Institute of Development Studies Bulletin. Vol. 10, No.1. August 1978.

19. Weiss, John. "Practical Appraisal of Social Cost Benefit Analysis in Pakistan." (Tentative Title). New York: UNIDO. (Unpublished. Publication expected in 1979) 